\title{
Role of interface formation versus fibres properties in the mechanical behaviour of bio-based composites manufactured by Liquid Composite Molding processes.
}

Pierre-Jacques Liotier ${ }^{\mathrm{a}, *}$, Monica Francesca Pucci ${ }^{\mathrm{b}}$, Antoine Le Duigou ${ }^{\mathrm{c}}$, Antoine Kervoelen $^{\mathrm{c}}$, Jacopo Tirillód, Fabrizio Sarasini ${ }^{\mathrm{d}}$, Sylvain Drapier ${ }^{\mathrm{a}}$,

${ }^{a}$ Mines Saint-Etienne, Univ Lyon, CNRS, UMR 5307 LGF, Centre SMS, Departement MPE, F-42023 Saint-Etienne France

${ }^{b}$ C2MA, IMT Mines Alès, Univ Montpellier, Alès, France

${ }^{c}$ Univ Bretagne Sud, IRDL UMR CNRS 6027, Centre de recherche C. Huygens 56100

Lorient, France

${ }^{d}$ Chemical Engineering Materials Environment dept, Sapienza Universitá di Roma, Via Eudossiana 1800184 Rome, Italy

\section{Abstract}

The aim of this work was to study the effect of free surface energy modification of flax fibres by a thermal treatment on the mechanical behaviour of bio-based composites. It has been proved that this modification enhances the wettability of flax fibres by liquid epoxy resin and results in a lower porosity amount in composites. Tests to evaluate mechanical properties of elementary fibres, yarns and composites have been performed. The main outcome of this multiscale study, even if elementary fibres and yarns have been embrittled and interface properties have been lowered after thermal treatment, is that the mechanical behaviour of composites manufactured by Liquid Composite Molding (LCM) is better with treated fibres.

\footnotetext{
*Corresponding author

Email address: liotier@emse.fr (Pierre-Jacques Liotier)
} 
Keywords: A-Natural fibres; B-Liquid Composite Molding; B-Porosity.

\section{Introduction}

Composite materials are, by design, characterised by the quality of the interface between their constituents. One of the main focus in developing innovative composite materials is to ensure a proper bonding between reinforcements and matrix. This bonding can result from covalent bonds or physico-chemical interactions. The strongest bonding results from covalent bonds and a modification of the chemistry of the fibre surface is often used in petro-sourced composites to induce chemical reactions with resin, such as epoxy. However, those kinds of surface treatment induce an increase of the carbon dioxide footprint of the overall process of composite manufacturing. Focusing on minimizing this footprint by the use of bio-based reinforcement $[1,2]$, the addition of a chemical treatment can counterbalance the gain from the environmental point of view. Low emission treatments have thus to be found.

Flax fibres are usually considered as adequate bio-reinforcements for composites [3], but their hydrophilic character makes them sensitive to moisture sorption and difficult to wet by hydrophobic resins $[4,5]$. Several ways have been explored to improve wettability and bonding of bio-based reinforcements by resins. In this work, a thermal treatment aiming at modifying the surface properties of flax fibres [6] has been applied to enhance their wettabillity, and thus modifying the impregnation of fibres by resins, decreasing at the same 
time their sensitivity to water sorption. The wettability of untreated and treated fibres has been assessed in a previous work [7], by measuring contact angles between the fibres and two test liquids: water and diiodomethane. Contact angles have been determined via the Wilhelmy relation, once the wetted length and the weight of the meniscus formed by the test liquid in contact with the fibre are known. Modification of wetted length during immersion in test liquids (due to fibres swelling or shrinking) was also taken into account $[7,8]$.

During manufacturing of biobased composites by Liquid Composite Moulding $(L C M)$ processes, such as Vacuum Assisted Resin Transfer Molding (VARTM) impregnation of fibres by the liquid resin can induce an imperfect interface and micro-porosity depending on the physicochemical affinity of liquid and solid phases. This family of composite manufacturing processes, being effective and low cost, is increasingly employed. It is then mandatory to understand the effect of the impregnation phenomena in order to match high quality requirements, especially for parts with a complex shape. However, a large amount of voids in bio-based composites manufactured by LCM processes have been observed [9] at different scales [10, 11].

The aim of the present study is to evaluate the effect of the modification of the free surface energy (by modifying one of its components) of flax fibres by a thermal treatment on the mechanical behaviour of flax reinforced biobased composites. It has already been proved [7] that this modification has the effect of enhancing the wettability of flax fibres by liquid epoxy resin, 
resulting in a lower porosity amount in composites reinforced by treated flax fibres.

It is well established that the surface chemical composition of fibres has an impact on wetting and thus on the impregnation dynamic. Polar and dispersive components of fiber surface energy, causing hydrophilic or hydrophobic behaviour of the reinforcement, have an effect on the interface formation during manufacturing but also on its toughness in the composite under service conditions. However, in literature a controversy still exists about the effective nature of surface energy and wetting behaviour of flax fibres $[5,12,13]$. Controlling the chemical surface state of such sustainable reinforcements is thus an issue of paramount importance, that has to be tackled with an approach that neither harms the environemental impact of the reinforcement processing and nor induces the production of unhealthy wastes.

Numerous studies $[1,14,15,16,17,18,19,20,21,22]$ have been devoted to the experimental methods dedicated to the measurements of mechanical properties of fibres and their interface with the matrix, without considering the formation of interfaces during manufacturing that affect the resulting properties.

The present paper thus details tests on treated and untreated fibres to evaluate mechanical properties of elementary fibres, yarns and composites. Tensile tests on elementary fibres, but also on yarns with different gauge length, have be performed. Composites mechanical properties have been investigated through Short Beam Shear Tests (SBST) and four points bending 
tests. In order to assess the effect of the surface energy modification on the interface toughness, microdroplets debonding tests on fibres have been performed with the same resin used for bio-based composites manufacturing.

The originality of this study is to give another point of view on studies that have proved the effects of the thermal treatment on swelling [8] and on void formation during manufacturing by LCM processes [7]. Indeed, the focus is here to understand the effect of treatment on the mechanical behaviour of elementary fibres, yarns, interface and then to extend these results at the scale of service conditions. These results will address the main issue of the impregnation quality of fibres and its effects at the scale of the composite and its application.

\section{Materials and methods}

\subsection{Materials}

Quasi-unidirectional flax fibres were provided by Libeco (FLAXDRY UD $\left.180^{\circledR}\right)$. The areal weight of the fabric is $180 \mathrm{~g} / \mathrm{m}^{2}$. Some fabrics were subjected to a thermal treatment at $220^{\circ} \mathrm{C}$ for $2 \mathrm{~h}$ under inert atmosphere $[6,7,8]$. Elementary fibres were all extracted from untreated and treated twisted yarns belonging to fabrics (Fig. 1).

The epoxy resin used for manufacturing composites by LCM processes and microdroplets was $\mathrm{SP} 106^{\mathrm{B}}$ provided by Gurit which cures rapidly at room temperature. 


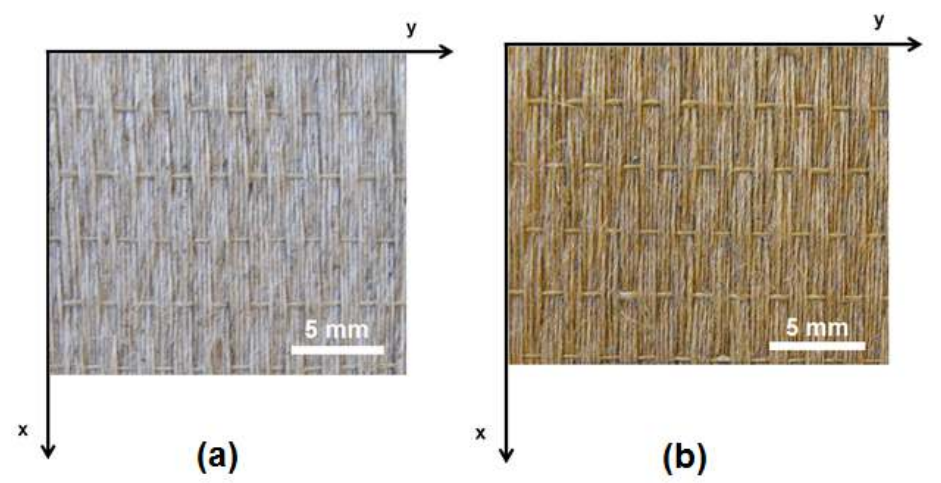

Figure 1: Untreated (a) and treated (b) flax fiber reinforcements

\subsection{Methods}

\subsubsection{At fibres scale}

\subsubsection{Tensile tests on single fibres}

Tensile tests were performed on 25 individual fibres for each batch. A gauge length of $10 \mathrm{~mm}$ was chosen. Samples were clamped on MTS type tensile testing machine equipped with a $2 \mathrm{~N}$ load cell. These tests were performed in a temperature and relative humidity controlled laboratory (23 $\left.\pm 0.5{ }^{\circ} \mathrm{C}, 48 \pm 2 \% \mathrm{RH}\right)$. Longitudinal mechanical properties under traction (apparent tensile modulus, strain and stress at break) of the different kind of elementary fibres were determined in accordance with the NFT 25-501-2 [23] standard. Compliance of the loading frame was taken into account. The considered mean diameter value of each fibre, required to calculate apparent modulus and strength, was taken as an average value from five measurements along the fibre with an optical microscope.

\subsubsection{Debonding of micro-droplets}


Resin droplets were placed on flax elementary fibres using a single glass fibre which had been dipped in the epoxy resin. Microbond specimens were then checked under the microscope to control the droplet geometry, length and height. Samples with defects (kink bands on the fibre or lack of symmetry of the droplet) were systematically rejected. Besides being symmetrical, microdroplets need to be smaller than $150 \mu \mathrm{m}$, the length to prevent fibre break. At least 25 specimens were tested for each test condition. Then the flax fibre with the epoxy microdroplet was mounted in the shearing device and continuously observed with a microscope. The fibre was pulled out of the droplet while the latter was constrained by knife edges. The loading rate during debonding was $0.1 \mathrm{~mm} \cdot \mathrm{min}^{-1}$. The apparent shear strength at debonding $\left(\tau_{a p p}\right)$ was calculated using the equation 1, from Miller et al. [24].

$$
\tau=\frac{F}{S_{e m b}}
$$

where $\tau$ corresponds to either the apparent shear stress at debonding $\tau_{a p p}$ or the friction stress after debonding friction. $F$ is either the debonding force or the friction force. $S_{e m b}$, the embedded surface area, corresponds to the bonded area between the fibre and the matrix.

\subsubsection{Mechanical tests on flax yarns}

When dealing with composite reinforcement, yarn characteristics need to be investigated. In the present work flax yarns have been characterized in terms of density, structure and mechanical properties. The density of un- 
treated and thermally treated flax yarns was measured by helium pycnometry (AccuPyc 1330) [25]. Yarn structure, in terms of twisting angle of flax fibres and yarn diameter, was determined by scanning electron microscopy (Philips XL40). In particular, five flax yarn samples for untreated and treated fibres (sputter coated with gold prior to examination), each of $15 \mathrm{~mm}$ in length, were observed, and within each sample, the fiber twisting angle and diameter were measured at 10 locations along the yarn. With regard to mechanical properties, the single yarns were tested using the same recommendations of the method described in ASTM C1557 [26]. Single yarns were carefully separated by hand from the fabric. Tensile tests were carried out at room temperature by means of a Zwick/Roell Z010 equipped with a $200 \mathrm{~N}$ load cell. Three different gauge lengths were tested, namely 20, 30, and $40 \mathrm{~mm}$, in order to measure the system compliance. Individual yarns were glued onto card tabs with a central window cut out to match the desired gauge length for the test. Tests were performed in displacement control at a crosshead speed of $2 \mathrm{~mm} \cdot \mathrm{min}^{-1}$. For each gauge length and fabric treatment, fifty yarns were tested. The mechanical properties of the flax quasi-UD fabric before and after thermal exposure was assessed according to ASTM D5035 [27]. Tensile tests were carried out at room temperature by means of a Zwick/Roell Z010 equipped with a $10 \mathrm{kN}$ load cell. One gauge length was used, i.e. $75 \mathrm{~mm}$, for specimens with a width equal to $25 \mathrm{~mm}$. Tests were performed in displacement control at a crosshead speed of $100 \mathrm{~mm} \cdot \mathrm{min}^{-1}$ to ensure failure within $20 \pm 3$ s. 


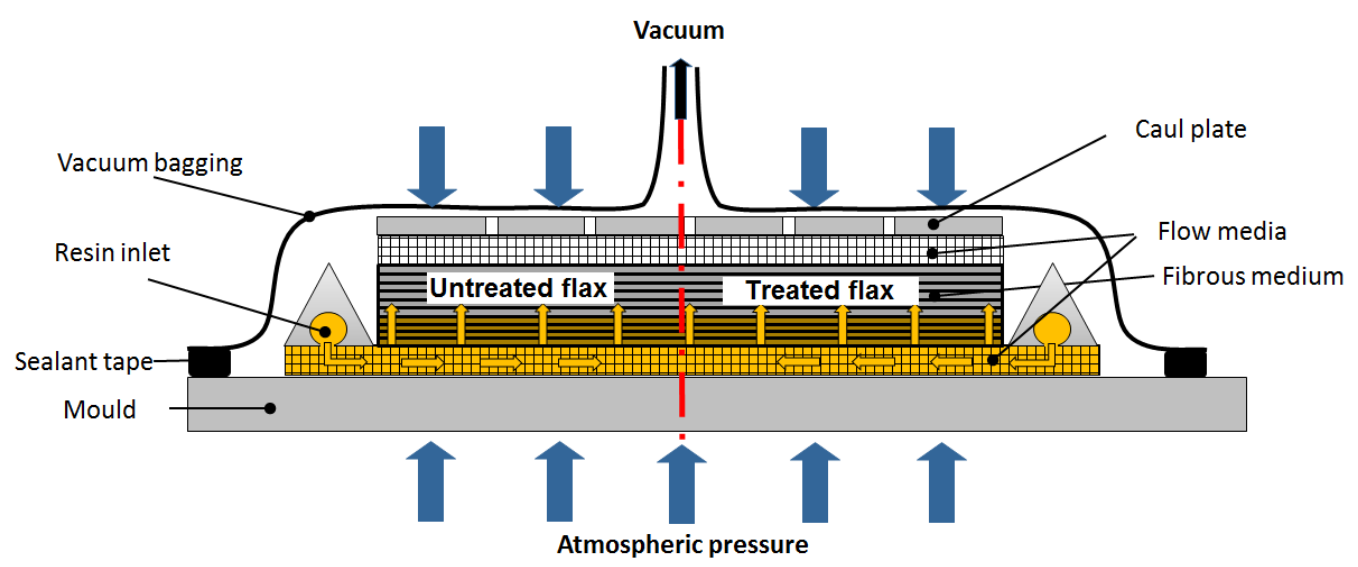

Figure 2: Infusion strategy with the two reinforcements [7]

\subsubsection{Bio-based composites manufacturing}

A composite plate was manufactured by Vacuum Assisted Resin Transfer Molding (VARTM). The infusion configuration used for this test is described in Fig. 2. The aim was to manufacture plates using both reinforcements, untreated and treated flax fabrics, in a single infusion $\left([0]_{10}\right)$ with the same processing conditions for the two types of reinforcements (Fig. 3). A distribution medium was placed under the preform to ensure the resin feeding. Another distribution medium was placed under the vent, which is located at the center of the top of the plate, to ensure the quality of the vacuum on the upper part of the preform. Infusion was performed at room temperature with the SP106 ${ }^{\circledR}$ resin. A 1.4 mbars vacuum was pulled, and resin was left entering until it could be visible in the outlet silicone pipe. 


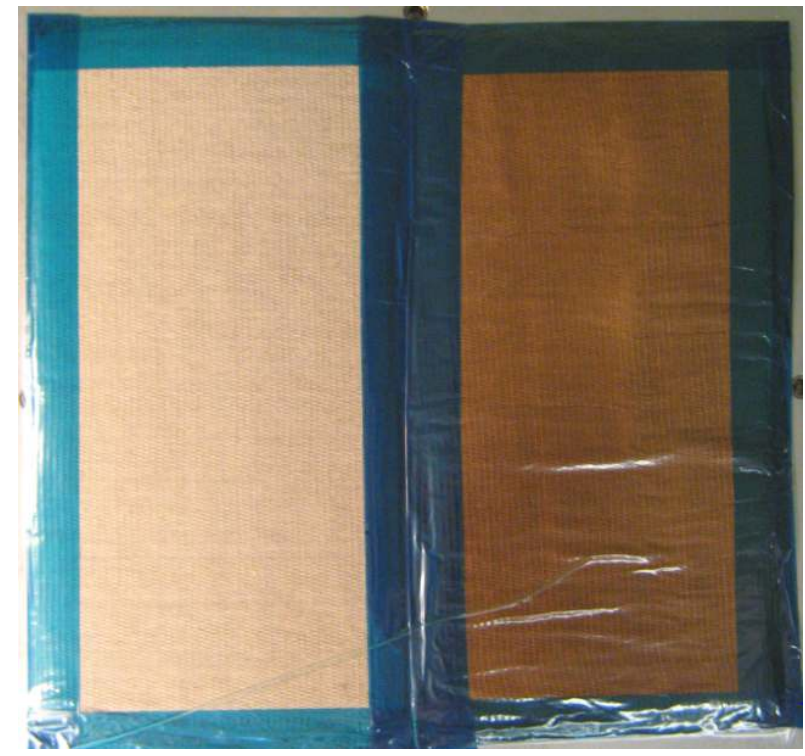

Figure 3: Preform with both reinforcements: untreated (left) and treated (right).

\subsubsection{At composites scale}

\subsubsection{Four points bending on flax reinforced composites}

To evaluate the flexural strength of manufactured composites, four points bending tests (Fig. 4) have been performed on samples reinforced by both treated and untreated flax fabrics. The distance between two consecutive supports is $20 \mathrm{~mm}$ for a total length between the external supports of $60 \mathrm{~mm}$, following ASTM D7264 [28]. Dimensions of samples were $75 \times 25 \times 3 \mathrm{~mm}^{3}$. A preload of $50 \mathrm{~N}$ and a travel speed of $1 \mathrm{~mm} / \mathrm{min}$ have been used. Six samples for each type of composites were tested.

\subsubsection{Beam Shear tests on flax reinforced composites}

Short Beam Shear Tests (SBST) have been conducted following ASTM 


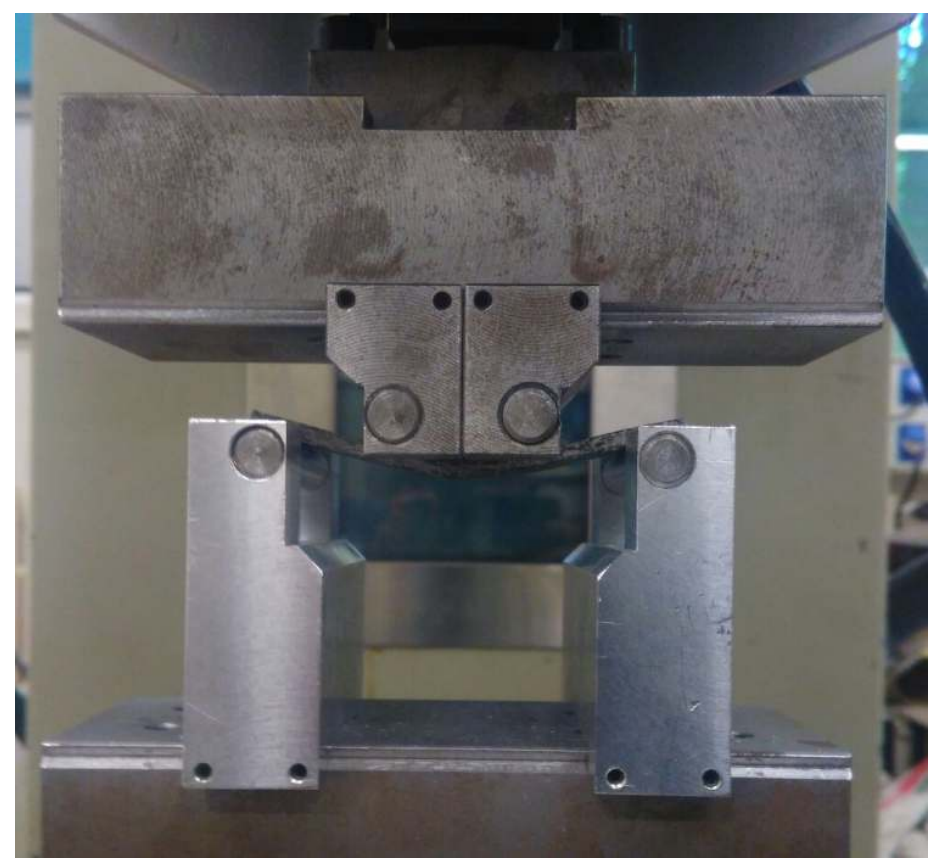

Figure 4: 4-point bending on a composite reinforced by untreated flax fabrics.

D2344 [29] in order to evaluate the interlaminar shear strength of both composites reinforced by treated and untreated flax fibres. Five samples for each type of composites were tested. Surface dimensions of the samples were $5 \times 30$ $\mathrm{mm}^{2}$. Thicknesses were measured as $3 \mathrm{~mm}$ for untreated flax reinforcements and $3.2 \mathrm{~mm}$ for treated reinforcements. This led to a small difference in the fiber volume ratio (41.4\% for flax fibres and $38.8 \%$ for treated flax fibres). To induce a failure in agreement with the standard (shear at the neutral axis) the spacing of the two bottom loading points has to be five times the thickness of the sample. It was thus set to $16 \mathrm{~mm}$ (Fig. 5). 


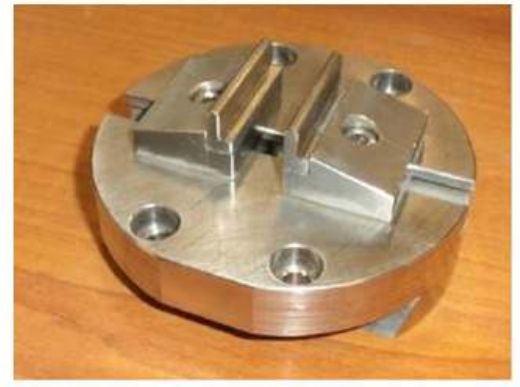

(a)

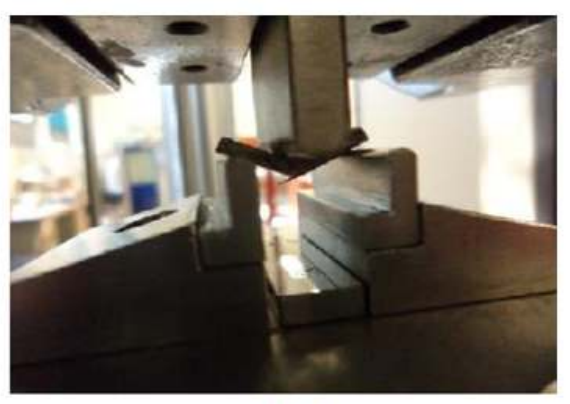

(b)

Figure 5: a) Short Beam Shear bench; b) Sample after failure during test.

\section{Results}

\subsection{Tensile properties of flax fibres}

Evaluation of the tensile modulus and strength requires the measurement of fibre diameters. Measurements performed in the present study confirm the ones made on fibres from the same fabric in a previous work [8]. It also confirms that the thermal treatment has no effect on the fibres morphology. Results obtained after tensile tests are summarized in Table 1.

\begin{tabular}{|c|c|c|c|c|}
\hline Materials & $\begin{array}{c}\text { Diameter } \\
(\mu \mathrm{m})\end{array}$ & $\begin{array}{c}\mathbf{E}_{\text {fibre }} \\
(\mathrm{GPa})\end{array}$ & $\begin{array}{c}\text { Strength } \\
(\mathrm{MPa})\end{array}$ & $\begin{array}{c}\text { Strain at } \\
\text { failure (\%) }\end{array}$ \\
\hline Untreated fibres & $16.4 \pm 4.1$ & $39 \pm 11$ & $1009 \pm 392$ & $2.50 \pm 1.40$ \\
\hline Treated fibres & $16.0 \pm 4.0$ & $38 \pm 10$ & $447 \pm 216$ & $1.50 \pm 0.60$ \\
\hline
\end{tabular}

Table 1: Tensile properties obtained on both untreated and treated elementary flax fibres

Results obtained on untreated fibres can be compared to literature [30]. Values of tensile modulus and tensile strength are relatively moderate. It can be due to the quality of the fibres itself or to the fabric manufacturing 
processes. Indeed, the values of literature [30] have been obtained from elementary fibres that have been directly extracted from flax slivers.

The main result here is that the tensile modulus is not modified by the thermal treatment. On the other hand, a strength loss of about 50\% was recorded after thermal treatment. This effect has been observed in the literature [31] but, again, on elementary fibres that were not extracted from a fabric. This loss of tensile strength can suggest a hornification mechanism or a degradation of cellulosic constituents [31]. This could be due to a progressive and irreversible modification of biochemical structure of fibres, like pectins [32], hemicellulose [33] or even non cristalline fibrillar cellulose [34]. Thus, Gassan and Bledzki [35] evidenced that the structural properties of cellulose, hemicelluloses and pectines may be altered by high temperature. Additional and specific investigations are needed to get insight into this degradation of tensile strength.

\subsubsection{Interfacial bond strength}

The micro-droplet debonding test on both treated and untreated fibres allowed to calculate an InterFacial Shear Strength (IFSS) for the fibre/matrix interface but also the friction stress after debonding. Values obtained from those tests are summarized in Table 2.

Again, results on untreated fibres appear to be lower than those for elementary fibres before weaving process $[36,37]$. The same conclusion can be drawn from the friction but the scatter makes this statement unsure. This 


\begin{tabular}{|c|c|c|}
\hline Materials & IFSS (MPa) & Friction stress (MPa) \\
\hline Untreated fibres & $10.7 \pm 2.2$ & $2.7 \pm 2.8$ \\
\hline Treated fibres & $7.0 \pm 2.0$ & $3.1 \pm 1.0$ \\
\hline
\end{tabular}

Table 2: Values obtained from micro-droplet debonding tests

may be due to the nature of the fibre itself but most likely the twisting and weaving processes to make yarns and fabrics are harmful for fibre surfaces.

It is clear that the treatment has a significant effect on the IFSS estimated by these tests. The reduction is of approximatly 30\%. As for the friction stress, it is not significantly modified by thermal treatment, even if the scatter seems to be reduced on the treated fibres. The interfacial bonding is thus significantly weakened after treatment. This result was indeed predictable since the surface free energy was lowered by a weakening of its polar component as it was proved in previous studies $[7,38]$ by tensiometric methods $[39,40]$. Indeed, considering the bonding energy calculated with the surface energies of both constituents, the interfacial strength should be lowered as one of the surface energies have been lowered by treatment. However, it is not the only parameter that should be taken into account for interfacial interactions since the fibres roughness could have an effect on mechanical interlocking. The effect of the thermal treatment on the fibres surface roughness will be investigated in further studies using some specific techniques such as the Atomic Force Microscopy (AFM) [40]. 


\subsection{Effective modulus and tensile strength of treated and untreated flax yarns}

The density of flax yarns was found to be only slightly affected by the thermal treatment. Measured values for untreated and thermally treated flax fibres are $1.6098 \pm 0.0001 \mathrm{~g} . \mathrm{cm}^{-3}$ and $1.6113 \pm 0.0003 \mathrm{~g} . \mathrm{cm}^{-3}$, respectively. This slight difference can be ascribed to a relative higher cellulose content in the thermally treated fibres due to the thermal degradation of the less thermally stable constituents (for instance, hemicellulose) [41, 35]. Both values are higher than those usually reported for lignocellulosic fibres, that lie in the range $1.2-1.5 \mathrm{~g} . \mathrm{cm}^{-3}$ [42]. This is an indirect evidence of a high cellulose content with a high degree of crystallinity in the flax fibres under investigation, as the density of crystalline cellulose estimated from diffraction data is reported to be around $1.64 \mathrm{~g} \cdot \mathrm{cm}^{-3}$ [43]. SEM micrographs of the two flax yarns types at different magnifications (Fig. 6 and 7) show that the yarn structure consists of many individual fibres twisted with a right-handed angle with respect to the yarn axis (Z-twist). From the images at higher magnification, it is evident that fibres cannot be considered as homogeneous entities, but exhibit variations in cross-section area and twisting angle which governs the fibre orientation in aligned natural yarn composites and therefore the resulting mechanical properties.

Both flax yarns showed similar twisting angles, equal to $14.05 \pm 0.87^{\circ}$ and $15.01 \pm 1.83^{\circ}$ for untreated and thermally treated fibres, respectively, while the apparent yarn diameter was found to exhibit a negative relationship with regard to the twisting angle: the apparent yarn diameter is reduced when the 


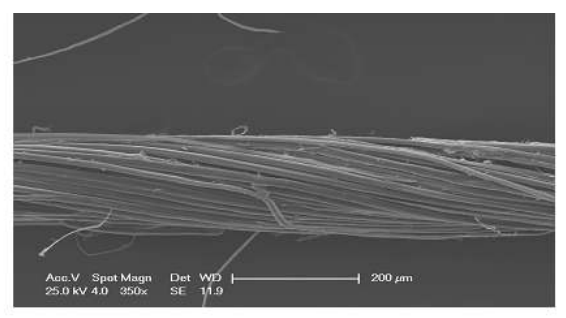

(a)

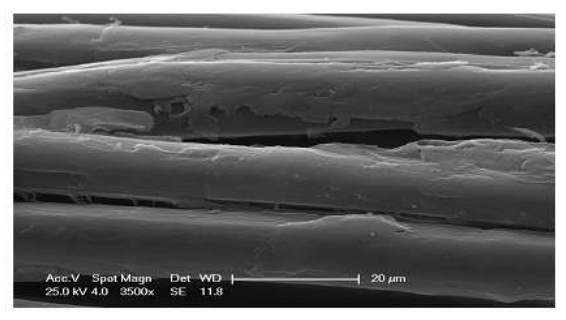

(c)

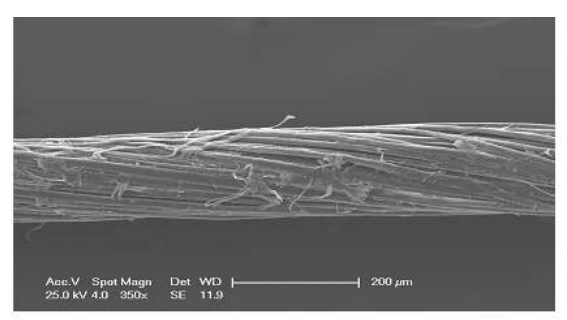

(b)

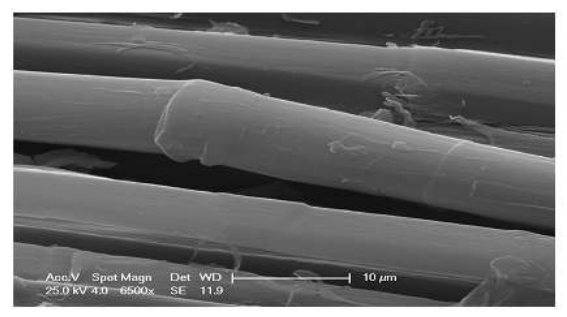

(d)

Figure 6: SEM micrographs of untreated flax yarn

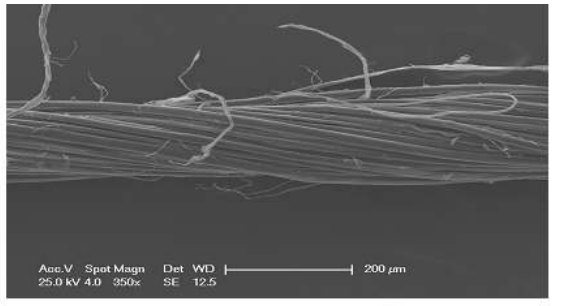

(a)

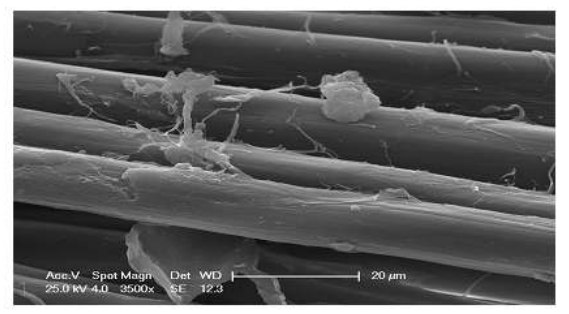

(c)

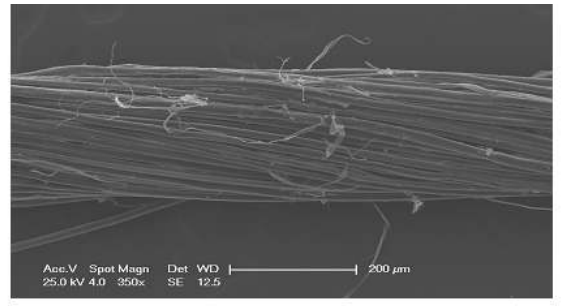

(b)

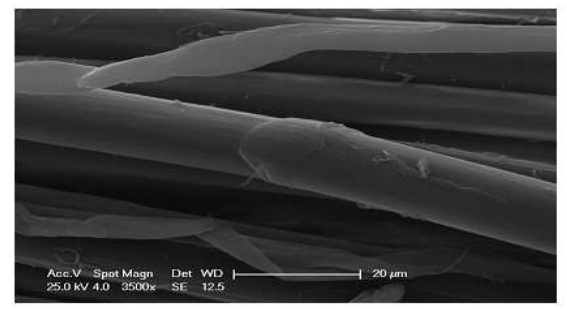

(d)

Figure 7: SEM micrographs of thermally treated flax yarn 
fibre twisting angle is increased, as already observed for hemp yarns [44]. In particular, the yarn diameter was $250.92 \pm 41.01 \mu m$ and $235.35 \pm 41.80 \mu m$ for untreated and thermally treated flax yarns, respectively. The thermal treatment did not seem to alter in a significant way the surface features of the flax yarns. Despite the lower fibre twisting angle of untreated fibres, the mechanical properties were found to be markedly reduced as a result of the thermal exposure, as can be noted from the results summarized in table 3. It is to be noted that no clear effect of gauge length can be observed for breaking stress and strain at failure, while the values for untreated flax yarns compare quite favourably with those reported by Madsen et al. [44] for hemp yarns $(19.4-19.5 \mathrm{~N})$. In this work the authors reported also data for hemp yarns after a short thermal treatment $(15 \mathrm{~min})$ in the range $180-220{ }^{\circ} \mathrm{C}$ and a decrease in ultimate stress was detected. This behaviour is ascribed to the thermal degradation of cellulosic fibres, which is mainly due to the scission of cellulose chains and depolymerization [35, 45].

\begin{tabular}{|c|c|c|}
\hline Specimen type & Breaking force (N) & Strain-at-failure (\%) \\
\hline UF $20 \mathrm{~mm}$ & $18.43 \pm 3.15$ & $2.61 \pm 0.29$ \\
UF $30 \mathrm{~mm}$ & $17.04 \pm 3.18$ & $2.33 \pm 0.26$ \\
UF $40 \mathrm{~mm}$ & $18.01 \pm 3.25$ & $2.49 \pm 0.24$ \\
\hline TF $20 \mathrm{~mm}$ & $11.14 \pm 1.99$ & $1.66 \pm 0.17$ \\
TF $30 \mathrm{~mm}$ & $9.74 \pm 2.06$ & $1.47 \pm 0.21$ \\
TF $40 \mathrm{~mm}$ & $10.88 \pm 1.94$ & $1.52 \pm 0.14$ \\
\hline
\end{tabular}

Table 3: Mechanical properties of untreated (UF) and thermally treated (TF) flax yarns

The enhanced brittle behaviour and cellulose degradation caused by ther- 


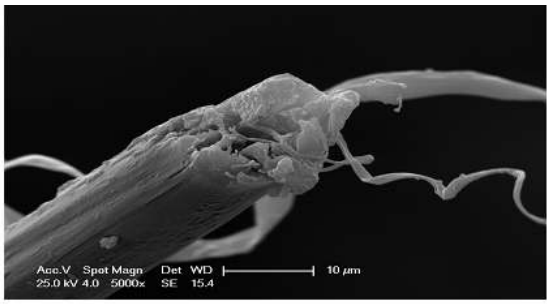

(a)

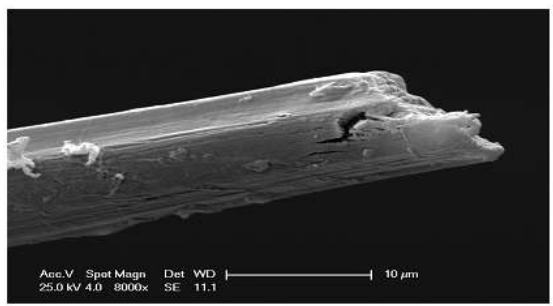

(c)

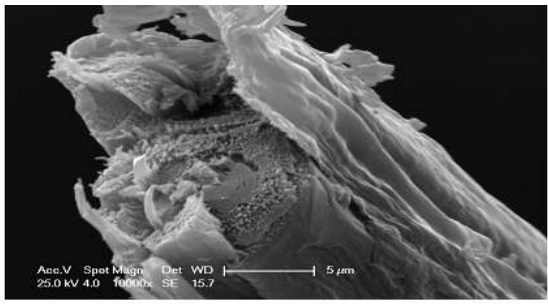

(b)

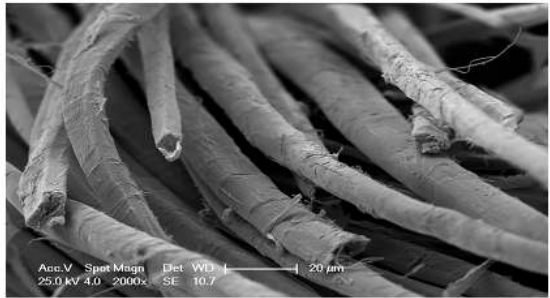

(d)

Figure 8: SEM micrographs of untreated flax yarns after tensile failure

mal exposure did not result in a change in the fracture modes of flax yarns, as confirmed by SEM images reported in Fig. 8 and 9, where a brittle behaviour with the absence of significant fibril splitting can be observed.

The reduction of mechanical properties at the yarn scale due to the thermal treatment resulted also in a significant strength loss of the whole quasi-UD fabric, which dropped from $1427.88 \pm 61.07 \mathrm{~N}$ for untreated flax, to $742.54 \pm 48.75 \mathrm{~N}$ after thermal treatment, thus confirming some degradation effect of the cellulose and of the cell wall materials. 


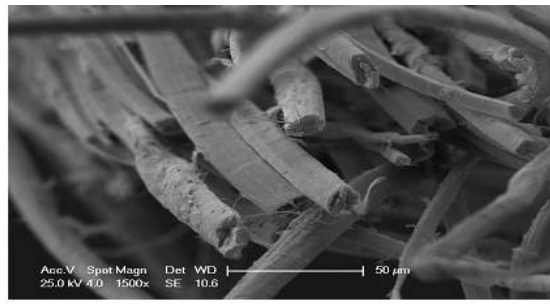

(a)

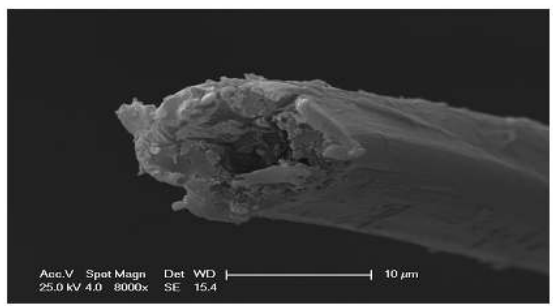

(c)

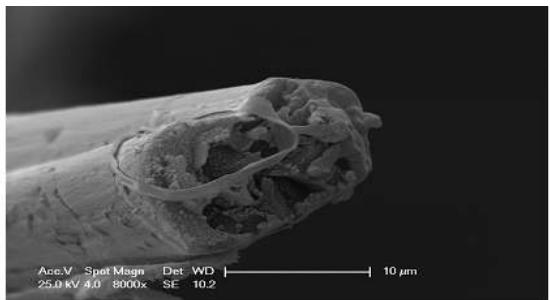

(b)

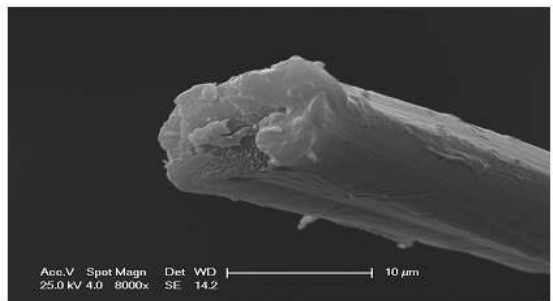

(d)

Figure 9: SEM micrographs of thermally treated flax yarns after tensile failure

\subsection{Shear strength of treated and untreated flax reinforced composites}

Five samples of composites reinforced by treated and untreated flax fabrics have been tested, and force-displacement graphs are shown in Fig. 10. It appears that the trend is not linear for the composite reinforced with untreated flax fibres. This could be due to gradual damage growth reflected in a loss of linear behaviour (the curve is linear up to a displacement of about $0.1 \mathrm{~mm})[46]$.

On the contrary, for the composite reinforced with treated flax fibres, the trend is linear up to rupture, which is similar to composites reinforced with synthetic fibres. In addition, samples examined after rupture (Fig. 11) show a difference. Untreated flax reinforced composites show a nonconform rupture to SBST standard but closer to a tensile failure due to 
bending. Composites reinforced with treated flax fibres exhibit a failure due to interlaminar shear, as expected in SBST tests for Inter Laminar Shear Strength (ILSS) characterisation.

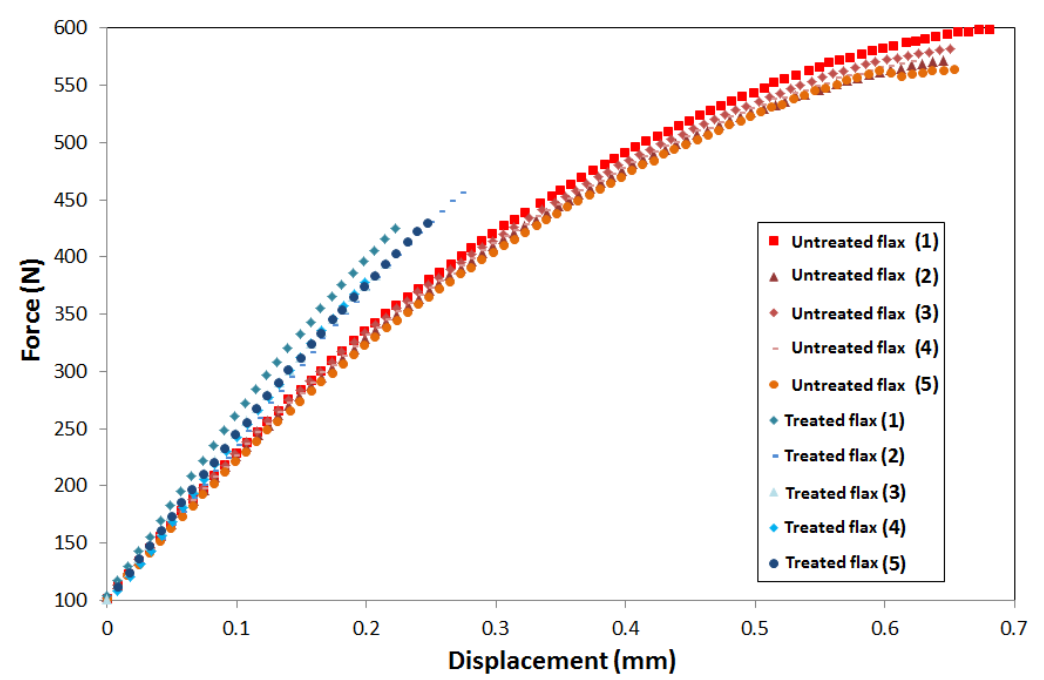

Figure 10: SBST experimental curves for composites reinforced by treated and untreated flax.

The shape of the force-displacement curves obtained with untreated flax is not common for this kind of test, and thus it is not possible to reach a direct conclusion. Therefore, a direct comparison between strengths of composites reinforced with both treated and untreated flax cannot be made. It can be seen that composites reinforced with untreated flax show a failure on the tensile side when the deflection becomes significant (Fig. 11 - left). Composites reinforced with treated flax show a linear behaviour under SBST and a breakage that complies with shear at neutral axis (Fig. 11 - right). The shear stress calculated can thus be considered as an ILSS at neutral axis 
for composites reinforced by treated fibres only. These stresses for untreated fibre reinforced composites are given for information, keeping in mind the non-linear response.

\begin{tabular}{|c|c|c|}
\hline Sample & $\tau_{x y}^{s}(M P a)$ & $\tau_{x y}^{r}(M P a)$ \\
\hline Untreated flax (1) & 16.5 & 29.9 \\
Untreated flax (2) & 16.5 & 28.5 \\
Untreated flax (3) & 16.2 & 28.2 \\
Untreated flax (4) & 16.6 & 28.2 \\
Untreated flax (5) & 16.7 & 28.2 \\
\hline Treated flax (1) & 19.6 & 19.6 \\
Treated flax (2) & 21.2 & 21.2 \\
Treated flax (3) & 18.7 & 18.7 \\
Treated flax (4) & 16.8 & 16.8 \\
Treated flax (5) & 19.7 & 19.7 \\
\hline
\end{tabular}

Table 4: Stress calculated at first damage $\left(\tau_{x y}^{s}\right)$ and at break $\left(\tau_{x y}^{r}\right)$, for each short beam shear test.

A maximum shear stress at break $\tau_{x y}^{r}$ has been calculated for treated flax. For untreated flax, the stress corresponding to the loss of linearity $\tau_{x y}^{s}$, has also been calculated. Results for each test are presented in Tab 4. For treated flax, stress at break can be estimated at $\tau_{x y}^{r}=19.2 \pm 1.6 \mathrm{MPa}$. For untreated flax, the first damage can be estimated at $\tau_{x y}^{s}=16.3 \pm 0.4 M P a$, but the stress at break is $\tau_{x y}^{r}=28.8 \pm 0.7 M P a$ due to the non-linear response. Considering the first value, it can be supposed that the better impregnation of the resin into the fibre network leads to an increase of the interface tougthness, but considering values at break, the conclusion would be the opposite. On the contrary, the non-linear response for untreated fibres can suggest a dif- 
ferent mechanism of damaging such as, for example, slipping of fibres in the composites, leading to bending rather than shear failure. These results have to be commented along with other tests in order to draw a conclusion, that is why four-point bending tests have been performed on the same composites.

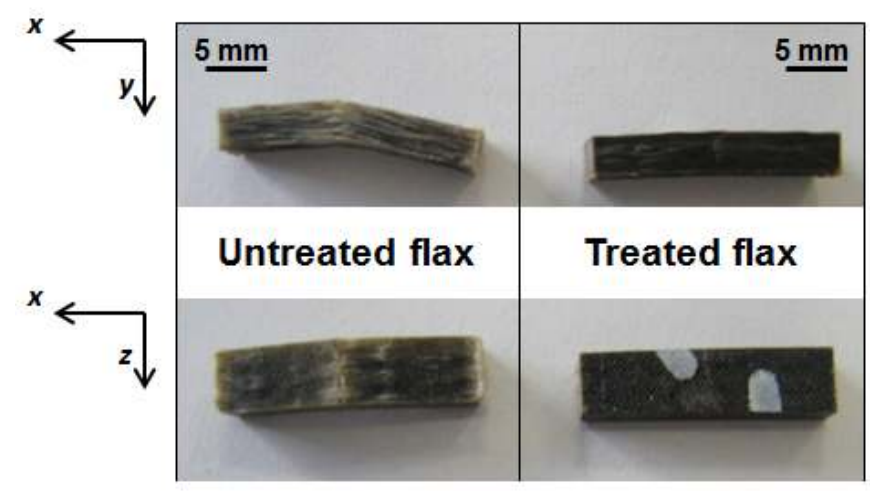

Figure 11: Samples after short beam shear tests 


\subsection{Flexural strength and modulus}

Six tests for each type of reinforcements have been conducted on composite samples extracted from half plates manufactured by LCM. Fig. 12 shows the force-displacement curves, which compare quite favourably with data from literature [47]. Both types of composite have a non-linear behaviour, but for lower loads for untreated fibres. According to SBST results, composites reinforced with treated flax show a higher stiffness. And again, composites reinforced with treated flax have a more brittle behaviour compared to samples reinforced with untreated flax (Fig. 13).

It can be also seen in Fig. 12 that some samples reinforced with untreated flax show uncommon behaviour with a failure occurring out of the hinging points. This is likely due to severe impregnation problems. This kind of behaviour has not been observed in composites reinforced with treated flax, which appear to show more reproducible results.

Considering that the beam theory can be applied on those samples, it is possible to calculate an effective stiffness for each test. Fig. 14 summarizes the mean values of effective stiffness and the dispersion depicted as an envelope for both composites reinforced with untreated and treated flax. Samples that exhibited severe impregnation problems leading to a non conform mechanical behaviour have been removed from the calculated mean and dispersion.

It can be seen in Fig. 14 that the behaviour is neither constant nor linear, as it would be expected with conventionnal composites. But it is clearly 


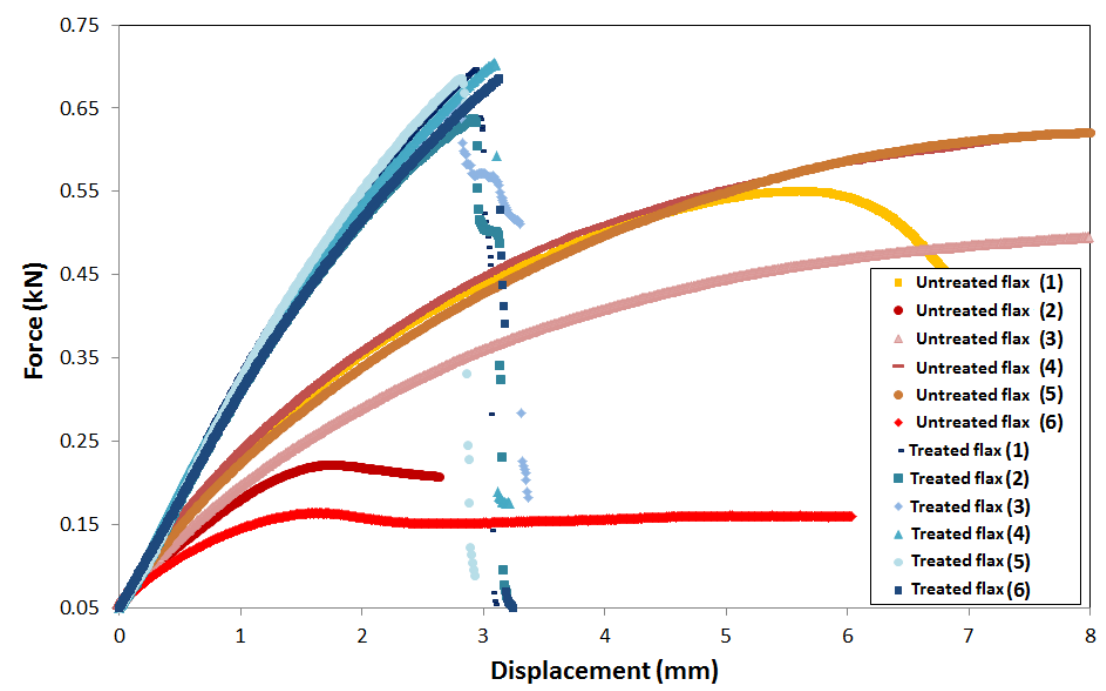

Figure 12: Experimental curves for composites reinforced by treated and untreated flax samples under 4 point bending.

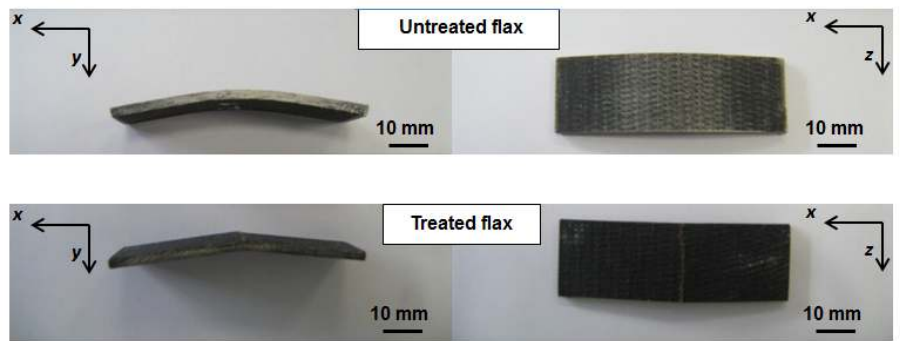

Figure 13: Samples after 4 points bending tests.

shown that composites reinforced with treated flax have a higher stiffness than the ones reinforced with untreated flax. Most important, maximal forces at failure that can be seen in Fig. 12 are reached for samples reinforced by treated flax, even if the strain at failure is lower. Corresponding stress at failure is more repeatable and higher compared to the same values calculated 


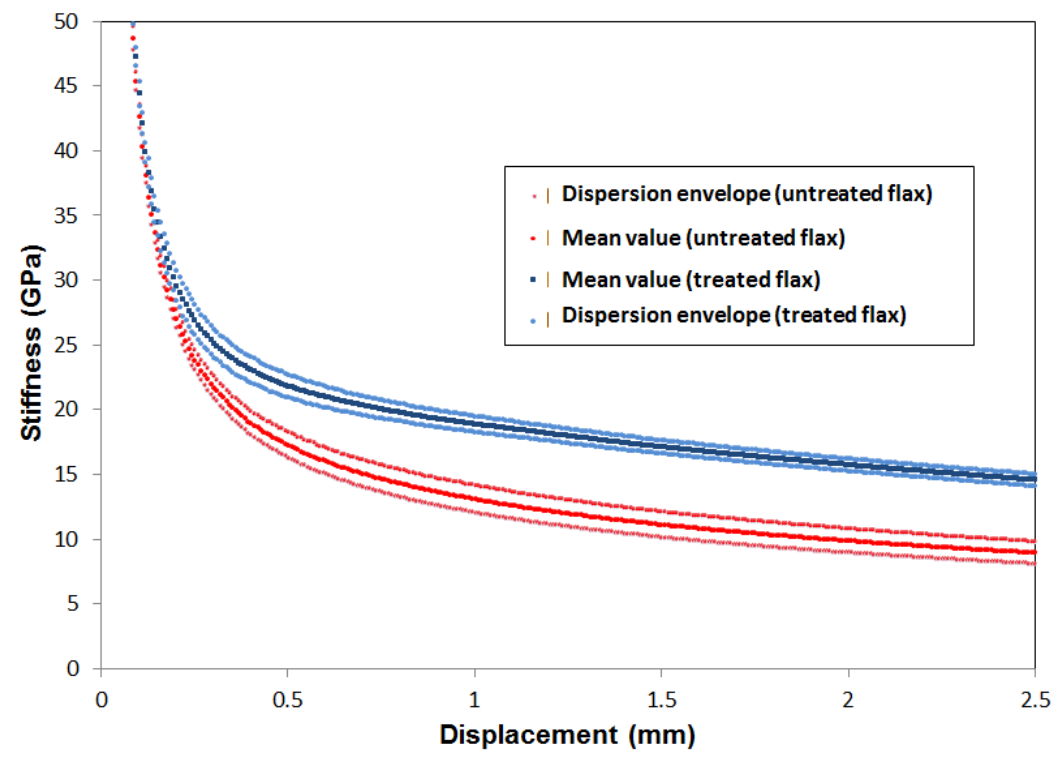

Figure 14: Mean stiffness against displacement during four-point bending test.

for composites reinforced with untreated flax fibres.

Following hypotheses of the beam theory for the entire duration of tests, stresses at failure $\sigma_{x x}^{r}$ have been calculated (Tab. 5). Mean values for stresses at failure for untreated (excluding untreated samples with impregnation problem) and treated flax fibres are 153.7 \pm 16.5 and $180.9 \pm 6.7 \mathrm{MPa}$, respectively.

\section{Discussions}

It has been proved by all results obtained at the scale of fibres and yarns that they have been embrittled by the thermal treatment : the stiffness has not been modified but the strain and stress at failure have been severely 


\begin{tabular}{|c|c|c|c|}
\hline Sample & $\sigma_{x x}^{r}(M P a)$ & Sample & $\sigma_{x x}^{r}(M P a)$ \\
\hline Untreated flax (1) & 146.7 & Treated flax (1) & 186.1 \\
Untreated flax (2) & 59.2 & Treated flax (2) & 170.1 \\
Untreated flax (3) & 133.7 & Treated flax (3) & 175.5 \\
Untreated flax (4) & 168.2 & Treated flax (4) & 187.7 \\
Untreated flax (5) & 166.2 & Treated flax (5) & 183.0 \\
Untreated flax (6) & $\mathbf{4 3 . 7}$ & Treated flax (6) & 182.8 \\
\hline
\end{tabular}

Table 5: Stresses at failure $\sigma_{x x}^{r}$ calculated for each 4-point bending test.

lowered. Previous studies [7] have proved that the thermal treatment tends to reduce the polar component of the surface energy of flax fibres. This has also the effect of lowering the total surface energy of fibres. Following that statement, the associated bonding energy should also be lowered considering an interface between treated fibres and a polymer matrix (epoxy in this case) compared to a similar interface with untreated flax fibres. This assumption was verified with the interfacial bond strength that was measured in the present study. The apparent shear strength for treated flax fibres and epoxy resin has been lowered by $30 \%$ compared to untreated flax fibres with the same resin. According to a basic rule of mixture with similar fibre volume fractions, properties of the composites should be lowered too. However, previous studies [7] have shown that manufacturing composites by LCM processes like VARTM, both overall void content and micro-voids content in a composite reinforced with treated flax are lower than in a composite reinforced with untreated flax manufactured in the same conditions. Mechanical tests, performed on a plate manufactured in the same condition 
than for the void content characterization from Pucci et al. [7], have shown that mechanical properties are enhanced in terms of stiffness and strength for composites reinforced with treated flax. This tends to prove that the impregnation process is more important than the intrinsic mechanical properties of both elementary fibres and interfaces with polymers. Thus, the quality of impregnation and the micro-void content in bio-based composites can not be neglected compared to the choice of the fibres themselves. This should lead to rethink the selection of fibres for bio-based composites which is, for now, only focused on the fibres mechanical properties, ignoring the manufacturing of the resulting composites.

\section{Conclusion}

Effects of the thermal treatment developed and used in previous studies on flax fibres $[6,7,8]$ were investigated from the mechanical point of view. Previous results have proved [7] that the thermal treatment modifies the overall surface energy of elementary fibres. This has an impact on wetting dynamics $[6,8]$, thus modifying the void content of composites manufactuered by LCM processes both at the macroscopic and microscopic scale.

It was demonstrated during the present study that the thermal treatment has a negative impact on elementary fibres and yarns strength. The effective stiffness of fibres and yarns does not seem to be impacted by the thermal treatment.

It was also proved that the interfacial strength between treated fibres and 
resin has been lowered compared to interfacial strength between untreated fibres and the same resin. This result was predictable because of the reduction in the overall surface energy of treated fibres, but it has been confirmed by mechanical tests.

Mechanical tests at the scale of composites have also been conducted. Composite plates, from which samples were taken, were manufactured by LCM processes, following the same methodology used for void content characterisation purpose in a previous work [7]. Results indicate that the mechanical behaviour of composites manufactured with both types of reinforcements is different, and the flexural strength was found to be higher for composites based on thermally treated fibres.

It can be concluded that even if elementary fibres and yarns have been embrittled and interface properties have been lowered after thermal treatment, since the wettability of fibres has been improved, the overall mechanical behaviour of composites manufactured by LCM is better with treated fibres. Thus, the impregnation during LCM, related to microvoids formation, is more critical than the mechanical behaviour of fibres, since the interface appears to be preponderant in the bio-composite mechanical properties. Rule of mixtures is thus not sufficient for describing composites mechanical behaviour if the fiber/matrix interface is not perfect. Further studies will focus on the description of the degree of imperfection of interfaces, including this parameter in simulations and models to correct the interfacial strength estimation and predict the behaviour of interfaces in a composite under service 
conditions. A full characterisation of the environmental impact of the treatment compared to composites behaviour enhancement has also to be carried out.

\section{Reference}

[1] H. Ku, H. Wang, N. Pattarachaiyakoop, M. Trada, A review on the tensile properties of natural fiber reinforced polymer composites, Composites Part B: Engineering 42 (4) (2011) 856-873.

[2] K.-t. Lau, P.-y. Hung, M.-H. Zhu, D. Hui, Properties of natural fibre composites for structural engineering applications, Composites Part B: Engineering 136 (2018) 222-233.

[3] L. Yan, N. Chouw, K. Jayaraman, Flax fibre and its composites-a review, Composites Part B: Engineering 56 (2014) 296-317.

[4] Y. Zhou, M. Fan, L. Chen, Interface and bonding mechanisms of plant fibre composites: An overview, Composites Part B: Engineering 101 (2016) 31-45.

[5] C. Baley, F. Busnel, Y. Grohens, O. Sire, Influence of chemical treatments on surface properties and adhesion of flax fibre-polyester resin, Composites Part A: Applied Science and Manufacturing 37 (10) (2006) $1626-1637$. 
[6] M. F. Pucci, P.-J. Liotier, S. Drapier, Capillary effects on flax fibersmodification and characterization of the wetting dynamics, Composites Part A: Applied Science and Manufacturing 77 (2015) 257-265.

[7] M. F. Pucci, P.-J. Liotier, D. Seveno, C. Fuentes, A. Van Vuure, S. Drapier, Wetting and swelling property modifications of elementary flax fibres and their effects on the liquid composite molding process, Composites Part A: Applied Science and Manufacturing 97 (2017) 3140.

[8] M. F. Pucci, P.-J. Liotier, S. Drapier, Capillary wicking in flax fabricseffects of swelling in water, Colloids and Surfaces A: Physicochemical and Engineering Aspects 498 (2016) 176-184.

[9] R. Umer, S. Bickerton, A. Fernyhough, The effect of yarn length and diameter on permeability and compaction response of flax fibre mats, Composites Part A: Applied Science and Manufacturing 42 (7) (2011) $723-732$.

[10] D. H. Lee, W. I. Lee, M. K. Kang, Analysis and minimization of void formation during resin transfer molding process, Composites Science and Technology 66 (16) (2006) 3281-3289.

[11] C. H. Park, A. Lebel, A. Saouab, J. Bréard, W. I. Lee, Modeling and simulation of voids and saturation in liquid composite molding processes, 
Composites Part A: Applied Science and Manufacturing 42 (6) (2011) 658-668.

[12] B. S. Westerlind, J. C. Berg, Surface energy of untreated and surfacemodified cellulose fibers, Journal of applied polymer science 36 (3) (1988) $523-534$.

[13] J. Van Hazendonk, J. Van der Putten, J. Keurentjes, A. Prins, A simple experimental method for the measurement of the surface tension of cellulosic fibres and its relation with chemical composition, Colloids and Surfaces A: Physicochemical and Engineering Aspects 81 (1993) 251261.

[14] N. Le Moigne, M. Longerey, J.-M. Taulemesse, J.-C. Bénézet, A. Bergeret, Study of the interface in natural fibres reinforced poly (lactic acid) biocomposites modified by optimized organosilane treatments, Industrial Crops and Products 52 (2014) 481-494.

[15] L. Soccalingame, A. Bourmaud, D. Perrin, J.-C. Bénézet, A. Bergeret, Reprocessing of wood flour reinforced polypropylene composites: impact of particle size and coupling agent on composite and particle properties, Polymer Degradation and Stability 113 (2015) 72-85.

[16] N. Le Moigne, M. Longerey, J. Taulemesse, J. Benezet, A. Bergeret, Improving the interface in natural fibres reinforced pla biocomposites by optimized organosilane treatments, Composites Part A. 
[17] I. M. De Rosa, J. M. Kenny, D. Puglia, C. Santulli, F. Sarasini, Morphological, thermal and mechanical characterization of okra (abelmoschus esculentus) fibres as potential reinforcement in polymer composites, Composites Science and Technology 70 (1) (2010) 116-122.

[18] A. Bourmaud, C. Morvan, A. Bouali, V. Placet, P. Perre, C. Baley, Relationships between micro-fibrillar angle, mechanical properties and biochemical composition of flax fibers, Industrial Crops and Products 44 (2013) 343-351.

[19] I. Van de Weyenberg, T. C. Truong, B. Vangrimde, I. Verpoest, Improving the properties of ud flax fibre reinforced composites by applying an alkaline fibre treatment, Composites Part A: Applied Science and Manufacturing 37 (9) (2006) 1368-1376.

[20] V. Placet, Characterization of the thermo-mechanical behaviour of hemp fibres intended for the manufacturing of high performance composites, Composites Part A: Applied Science and Manufacturing 40 (8) (2009) $1111-1118$.

[21] J. Andersons, E. Spārniņš, R. Joffe, L. Wallström, Strength distribution of elementary flax fibres, Composites science and technology 65 (3-4) (2005) 693-702.

[22] J. Blanchard, A. Sobey, J. Blake, Multi-scale investigation into the me- 
chanical behaviour of flax in yarn, cloth and laminate form, Composites Part B: Engineering 84 (2016) 228-235.

[23] Xp t25 501-2:2009 reinforcement fibres - flax fibres for plastics composites - part 2: Determination of tensile properties of elementary fibres.

[24] B. Miller, P. Muri, L. Rebenfeld, A microbond method for determination of the shear strength of a fiber/resin interface, Composites Science and Technology 28 (1) (1987) 17-32.

[25] T. Rude, L. Strait Jr, L. Ruhala, Measurement of fiber density by helium pycnometry, Journal of composite materials 34 (22) (2000) 1948-1958.

[26] Astm c1557 - 14 standard test method for tensile strength and youngs modulus of fibers.

[27] Astm d5035 - 11(2015) standard test method for breaking force and elongation of textile fabrics (strip method).

[28] Astm d7264m - 15 standard test method for flexural properties of polymer matrix composite materials.

[29] D2344 / d2344m- 16 standard test method for short-beam strength of polymer matrix composite materials and their laminates.

[30] C. Baley, A. Bourmaud, Average tensile properties of french elementary flax fibers, Materials Letters 122 (2014) 159-161. 
[31] C. Gourier, A. Le Duigou, A. Bourmaud, C. Baley, Mechanical analysis of elementary flax fibre tensile properties after different thermal cycles, Composites Part A: Applied Science and Manufacturing 64 (2014) 159166.

[32] C. Baley, C. Morvan, Y. Grohens, Influence of the absorbed water on the tensile strength of flax fibers, in: Macromolecular Symposia, Vol. 222, Wiley Online Library, 2005, pp. 195-202.

[33] C. Altaner, M. Jarvis, Modelling polymer interactions of the molecular velcrotype in wood under mechanical stress, Journal of theoretical biology 253 (3) (2008) 434-445.

[34] O. M. Astley, A. M. Donald, A small-angle x-ray scattering study of the effect of hydration on the microstructure of flax fibers, Biomacromolecules 2 (3) (2001) 672-680.

[35] J. Gassan, A. K. Bledzki, Thermal degradation of flax and jute fibers, Journal of Applied Polymer Science 82 (6) (2001) 1417-1422.

[36] A. Le Duigou, P. Davies, C. Baley, Exploring durability of interfaces in flax fibre/epoxy micro-composites, Composites Part A: Applied Science and Manufacturing 48 (2013) 121-128.

[37] A. Le Duigou, A. Kervoelen, A. Le Grand, M. Nardin, C. Baley, Interfacial properties of flax fibre-epoxy resin systems: existence of a complex interphase, Composites Science and Technology 100 (2014) 152-157. 
[38] A. Le Duigou, A. Bourmaud, E. Balnois, P. Davies, C. Baley, Improving the interfacial properties between flax fibres and plla by a water fibre treatment and drying cycle, Industrial Crops and Products 39 (2012) 31-39.

[39] M. F. Pucci, P.-J. Liotier, S. Drapier, Tensiometric method to reliably assess wetting properties of single fibers with resins: Validation on cellulosic reinforcements for composites, Colloids and Surfaces A: Physicochemical and Engineering Aspects 512 (2017) 26-33.

[40] M. F. Pucci, B. Duchemin, M. Gomina, J. Bréard, Temperature effect on dynamic wetting of cellulosic substrates by molten polymers for composite processing, Composites Part A: Applied Science and Manufacturing 114 (2018) 307-315.

[41] M. Z. Sefain, S. F. El-Kalyoubi, N. Shukry, Thermal behavior of holoand hemicellulose obtained from rice straw and bagasse, Journal of Polymer Science Part A: Polymer Chemistry 23 (5) (1985) 1569-1577.

[42] K. L. Pickering, M. A. Efendy, T. M. Le, A review of recent developments in natural fibre composites and their mechanical performance, Composites Part A: Applied Science and Manufacturing 83 (2016) 98112.

[43] Y. Nishiyama, J. Sugiyama, H. Chanzy, P. Langan, Crystal structure and hydrogen bonding system in cellulose i $\alpha$ from synchrotron x-ray 
and neutron fiber diffraction, Journal of the American Chemical Society 125 (47) (2003) 14300-14306.

[44] B. Madsen, P. Hoffmeyer, A. B. Thomsen, H. Lilholt, Hemp yarn reinforced composites-i. yarn characteristics, Composites Part A: Applied Science and Manufacturing 38 (10) (2007) 2194-2203.

[45] C. Baley, A. Le Duigou, A. Bourmaud, P. Davies, Influence of drying on the mechanical behaviour of flax fibres and their unidirectional composites, Composites Part A: Applied Science and Manufacturing 43 (8) (2012) 1226-1233.

[46] H. Cui, S. Koussios, Y. Li, A. Beukers, Measurement of adhesive shear properties by short beam shear test based on higher order beam theory, International Journal of Adhesion and Adhesives 40 (2013) 19-30.

[47] C. Poilâne, A. Vivet, L. Momayez, B. B. Doudou, M. Ayachi, J. Chen, Propriétés mécaniques de préimprégnés lin/époxyde, Comptes Rendus des JNC 16. 